INL/EXT-12-26114

\title{
Impact of Fission Products Impurity on the Plutonium Content in PWR MOX Fuels
}

\author{
Andrea Alfonsi \\ Gilles Youinou
}

March 2012

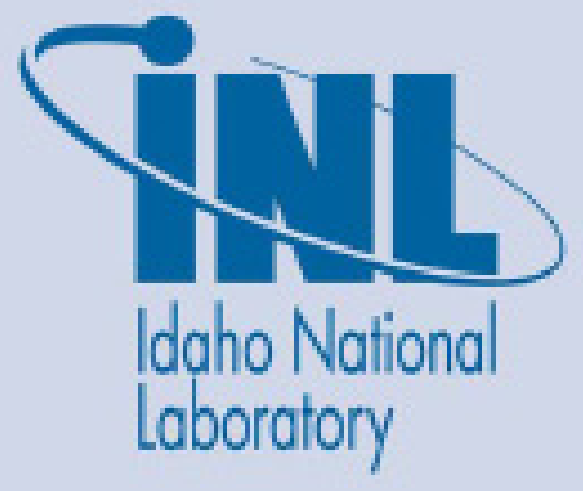

The INL is a U.S. Department of Energy National Laboratory operated by Battelle Energy Alliance 


\section{DISCLAIMER}

This information was prepared as an account of work sponsored by an agency of the U.S. Government. Neither the U.S. Government nor any agency thereof, nor any of their employees, makes any warranty, expressed or implied, or assumes any legal liability or responsibility for the accuracy, completeness, or usefulness, of any information, apparatus, product, or process disclosed, or represents that its use would not infringe privately owned rights. References herein to any specific commercial product, process, or service by trade name, trade mark, manufacturer, or otherwise, does not necessarily constitute or imply its endorsement, recommendation, or favoring by the U.S. Government or any agency thereof. The views and opinions of authors expressed herein do not necessarily state or reflect those of the U.S. Government or any agency thereof. 
INL/EXT-12-26114

\title{
Impact of Fission Products Impurity on the Plutonium Content in PWR MOX Fuels
}

\author{
Andrea Alfonsi \\ Gilles Youinou
}

March 2012

Idaho National Laboratory Idaho Falls, Idaho 83415

http://www.inl.gov

Prepared for the

U.S. Department of Energy

Office of Nuclear Energy

Under DOE Idaho Operations Office

Contract DE-AC07-05ID14517 


\section{Impact Of Fission Products Impurity On The Plutonium Content In PWR MOX Fuels}

INL/EXT-12-26114

March 2012

Approved by:

Name

Date

Title [optional]

Name

Date

Title [optional]

Name

Date

Title [optional]

Name

Date

Title [optional] 


\section{CONTENTS}

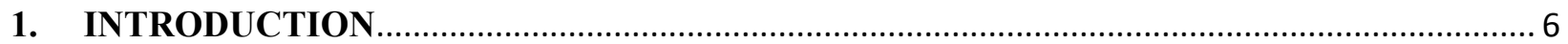

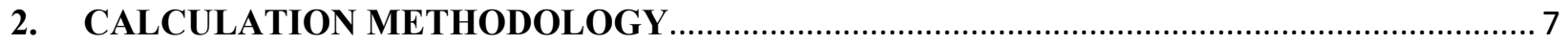

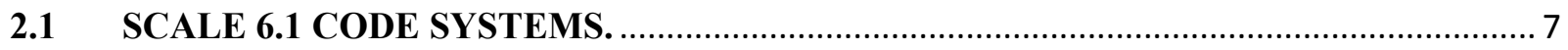

$2.2 \quad$ FUEL-CYCLE INTEGRATION and TRADEOFFS (FIT), ......................................... 9

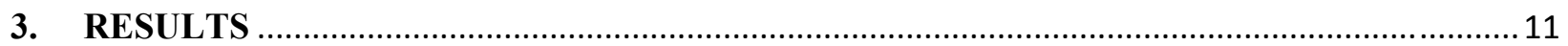

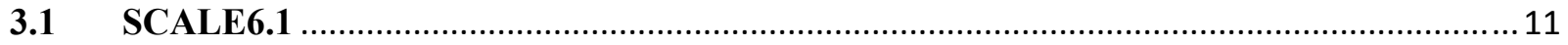

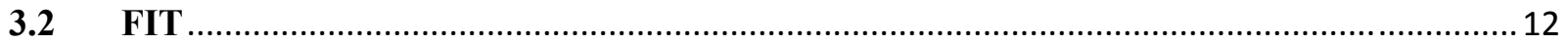

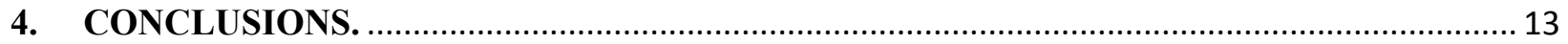

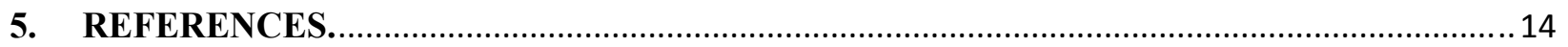

Appendix 1: List of non-gaseous fission products considered in the calculations...................... 15

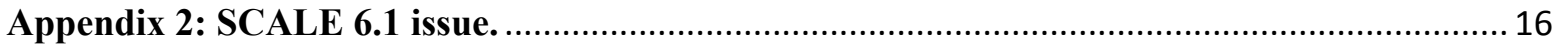




\section{Impact Of Fission Products Impurity On The Plutonium Content In PWR MOX Fuels}

\section{INTRODUCTION}

This report presents the results of a neutronics analysis in which the separation of the fission products (FP) during the reprocessing of UOX spent fuel assemblies (UOX SNF) is not perfect and that, consequently, a certain amount of FP goes into the Pu stream used to fabricate PWR MOX fuel assemblies. Only non-gaseous FP have been considered (see the list of 176 isotopes considered in the calculations in Appendix 1). This mixture of $\mathrm{Pu}$ and FP is called $\underline{P u^{F P}}$. Note that, in this preliminary analysis, the FP losses are considered element-independent, i.e., for example, $1 \%$ of FP losses mean that $1 \%$ of all non-gaseous FP leak into the Pu stream.

The main objective of these calculations is to quantity the increase of the Pu content of a PWR MOX fuel necessary to maintain the same average burnup at discharge (51 GWd/tIHM) independently of the amount of FP in the Pu stream, i.e. independently of the $P u^{F P}$ composition. The calculations are performed with SCALE6.1 as well as, in order to assess its validity, with the internally developed fuel cycle tool FIT.

The amount of $\mathrm{Pu}$ and FP present in the reference $51.0 \mathrm{GWd} / \mathrm{tIHM} \mathrm{UOX}$ SNF (4.3\% U-235) after 10 years of cooling time is given in Table 1.1 below. It shows that 1 ton of UOX SNF contains $11.33 \mathrm{~kg}$ of $\mathrm{Pu}$ and $44.05 \mathrm{~kg}$ of non-gaseous FP, hence, for example, if the FP losses are equal to $1 \mathrm{w} \%$, the $P u^{F P}$ mixture contains $11.33 \mathrm{~kg}$ of $\mathrm{Pu}$ and $0.4405 \mathrm{~kg}$ of non-gaseous $\mathrm{FP}$, or put in differently, $P u^{F P-1 \%}=96.26 \mathrm{w} \% \mathrm{Pu}+3.74 \mathrm{w} \%$ FP. The compositions of the $P u^{F P}$ mixture as a function of the FP losses during the reprocessing of UOX SNF are presented in Table 1.2.

\begin{tabular}{|c|c|}
\hline \multicolumn{1}{|c|}{ Isotope } & kg/tIHM \\
\hline $\mathrm{Pu} 238$ & 0.295 \\
\hline $\mathrm{Pu} 239$ & 6.153 \\
\hline $\mathrm{Pu} 240$ & 2.930 \\
\hline $\mathrm{Pu} 241$ & 1.086 \\
\hline $\mathrm{Pu} 242$ & 0.864 \\
\hline Total $\mathrm{Pu}$ & 11.33 \\
\hline Total FP & 52.64 \\
\hline Total FP $($ no-gas $)$ & 44.05 \\
\hline Ratio FP/Pu & 4.646 \\
\hline Ratio FP ${ }_{\text {no-gas }} / \mathrm{Pu}$ & 3.888 \\
\hline
\end{tabular}

Table 1.1. Pu and FP present in the reference $51 \mathrm{GWd} / \mathrm{tIHM}$ UOX SNF (10-year cooling time). 


\begin{tabular}{|c|c|c|}
\hline \multirow{2}{*}{ FP losses (w\%) } & $\begin{array}{c}\text { FP in the } \boldsymbol{P u}^{\boldsymbol{P F}} \\
\text { mixture (w\%) }\end{array}$ & $\begin{array}{c}\text { Pu in the } \boldsymbol{P u}^{\boldsymbol{P F}} \\
\text { mixture (w\%) }\end{array}$ \\
\hline $0.00 \%$ & $0.00 \%$ & $100.00 \%$ \\
\hline $0.01 \%$ & $0.04 \%$ & $99.96 \%$ \\
\hline $0.05 \%$ & $0.19 \%$ & $99.81 \%$ \\
\hline $0.10 \%$ & $0.39 \%$ & $99.61 \%$ \\
\hline $0.25 \%$ & $0.96 \%$ & $99.04 \%$ \\
\hline $0.50 \%$ & $1.91 \%$ & $98.09 \%$ \\
\hline $0.75 \%$ & $2.83 \%$ & $97.17 \%$ \\
\hline $1.00 \%$ & $3.74 \%$ & $96.26 \%$ \\
\hline $2.00 \%$ & $7.22 \%$ & $92.78 \%$ \\
\hline $3.00 \%$ & $10.45 \%$ & $89.55 \%$ \\
\hline $4.00 \%$ & $13.46 \%$ & $86.54 \%$ \\
\hline $5.00 \%$ & $16.28 \%$ & $83.72 \%$ \\
\hline
\end{tabular}

Table 1.2. Composition of the $P u^{F P}$ mixture as a function of the FP losses during the reprocessing of UOX SNF.

\section{CALCULATION METHODOLOGY}

The calculations needed by this study have been performed through two different codes:

- SCALE 6.1 code system;

- $\quad$ FIT (Fuel-cycle Integration and Tradeoffs) toolkit [7].

A small overview on the main capabilities and models used is reported in the following paragraphs.

\subsection{SCALE 6.1 CODE SYSTEMS.}

The reactor physics calculations have been performed by the lattice physics capabilities of the SCALE 6.1 code systems. The calculation flow consists of the use of several modules mutually coupled. The discrete-ordinates code NEWT (New ESC-based Weighting Transport code) coupled to the depletion code ORIGEN [8] via the TRITON control module [4]. Using the discrete-ordinates approximation to the transport equation on an arbitrary grid, together with a 238-group neutron cross-section library based on ENDF/B-VII, NEWT provides a robust and rigorous deterministic solution for non-orthogonal configurations. The differencing scheme employed by NEWT, the Extended Step Characteristic Approximation, allows a computational two-dimensional mesh based on arbitrary polygons. Such a mesh can be used to closely approximate curved or irregular surfaces to provide the capability to model problems that were formerly difficult or impractical to model directly with discrete-ordinates methods.

The TRITON control module performs the task of coordination of data transfer between various physics codes available within SCALE 6.1 and of invoking those codes in the proper sequence for a desired type of calculation. The high-fidelity nature of the NEWT solution in estimating angular flux distributions combined with the rigor of the ORIGEN depletion solver gives TRITON the capability to perform precise burnup-dependent physics calculations with few 
implicit approximations, and limited primarily by the accuracy of nuclide cross-sectional data. Such rigor may be necessary to capture the unique attributes of MOX fuel behavior as well as that of advanced, highly heterogeneous fuel assembly designs being deployed in currentgeneration reactors. Cross-sectional self-shielding is carried out by BONAMI for unresolvedrange resonance data; the resolved resonance processor module CENTRM performs a 1-D discrete-ordinates code that uses point-wise cross-section data to produce a set of continuousenergy fluxes at discrete spatial intervals for each unit cell. Following a CENTRM calculation, the code PMC uses the resulting flux to collapse the point-wise continuous-energy cross sections into multi-group cross sections for each nuclide in each material in a unit (e.g., pin cell). The result is a multi-group library in which point cross-sectional data are weighted using the explicit point-wise spectrum representative of the nuclides present in a pin cell. Effects from overlapping resonances, fissile material in the fuel and surrounding moderator, anisotropic scattering, and inelastic level scattering are explicitly handled by this approach.

For the physics calculations carried out during this study, a TRITON model of one fourth standard (17x17) fuel assembly has been used (Fig 2.1). All the MOX rods have the same U235 enrichment and the same Plutonium content. The $0.5 \mathrm{~mm}$ water gap at the periphery is explicitly represented. The model uses three different burn-up zones to take into account the different local moderating ratios: 1 for the corner rods (blue), 1 for the other rods located at the periphery (green) and 1 for the internal rods (red).

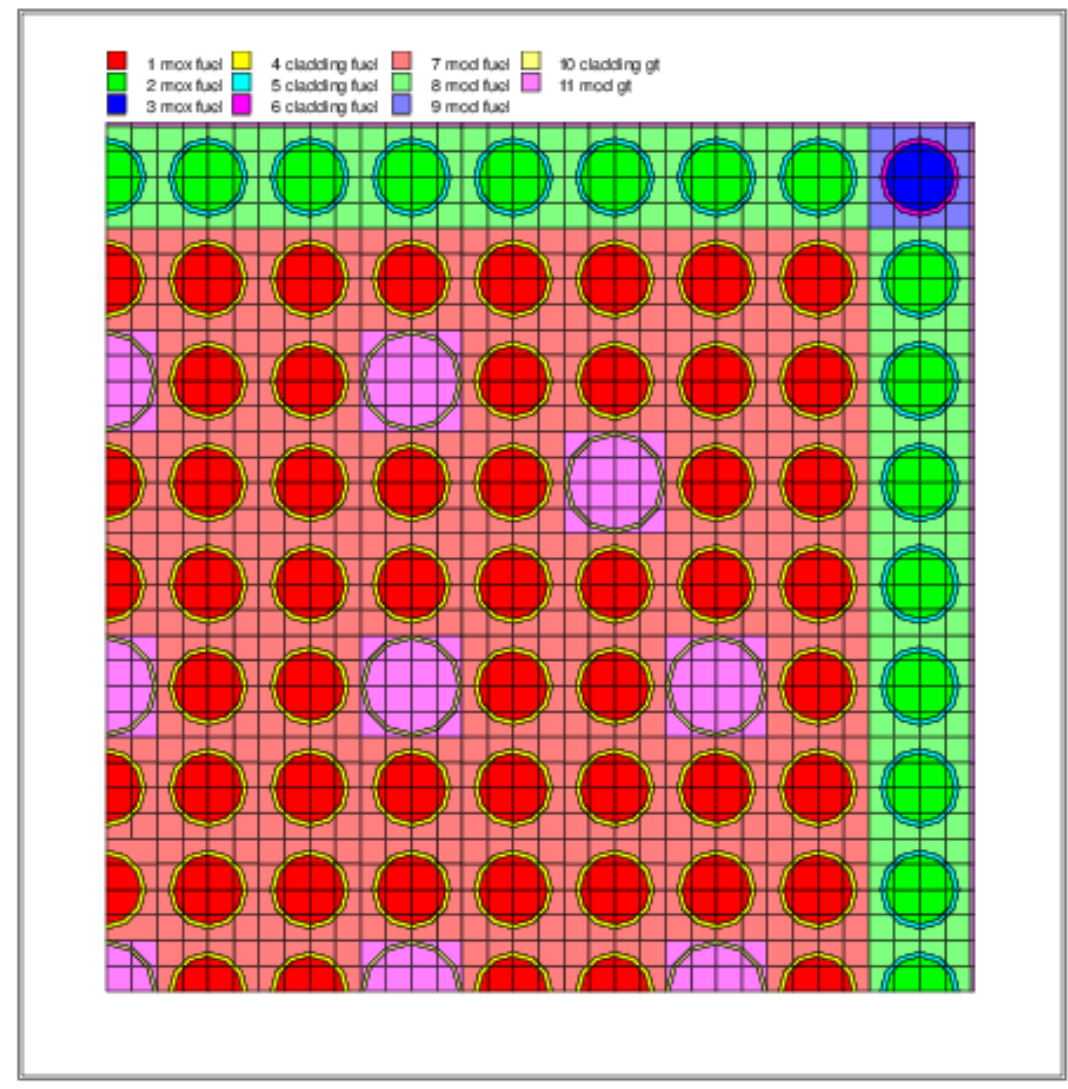

Fig 2.1. TRITON model (one fourth of a standard $17 \times 17$ fuel assembly) 
The plutonium content in the MOX fuel assemblies must be increased to compensate for the absorption of the fission products and thus maintain the same average burnup at discharge of 51 $\mathrm{GWd} / \mathrm{tIHM}$ independently of the amount of fission products in the plutonium stream. The calculations have been run considering a 3-batch core with an average discharge burn-up of 51.0 GWd/tIHM. The model takes in account 1 year fuel aging (time needed by the fabrication and transport operations).

The necessary $P u^{F P}(\mathrm{Pu}+\mathrm{FP})$ enrichments are determined with a methodology that is standard for this kind of application: the k-infinity of the assembly at the average end of cycle burn-up (34 $\mathrm{GWd} / \mathrm{tHM}$ ), without soluble boron, is equal to that of the reference $4.3 \%$ UOX assembly calculated using the same code (SCALE 6.1), methods (SN), nuclear data (238 group library based on ENDF/B - VII), etc., i.e. $\mathbf{k - i n f}=\mathbf{1 . 0 3 6 5}$ in our case. This is the strategy ensures the different fuels will release the same amount of energy and thus allows relevant comparisons among them.

\subsection{FUEL-CYCLE INTEGRATION and TRADEOFFS (FIT).}

The Fuel-cycle Integration and Tradeoffs toolkit [7] is a tool internally developed at the Idaho National Laboratory in order to permit a systematic examination of the chemical behavior of a FC and analyze different cases.

FIT is a method to examine different fuel cycles using common bases; in particular, to determine how changes in one part of a fuel cycle (say, fuel burn-up, cooling, or separation efficiencies) affect other parts of the it. FIT provides the following:

- Rough estimate of physics and mass balance feasibility of combinations of technologies. If feasibility is an issue, it provides an estimate of how performance would have to change to achieve feasibility;

- Estimate of impurities in fuel and impurities in waste as function of separation performance, fuel fabrication, reactor, uranium source, etc.

The following figure illustrates the basic mass flows. For the first recycle iteration (recycle-1), there are only the streams from incoming used fuel via separation-1. There is no mass flow yet from separation-2. For subsequent recycle streams, the TRU-U-1 product mass flow from separation-1 remains as before and the TRU-U-2 product mass from separation-2 from the previous iteration is added to create a combined TRU-U product stream. FIT uses a single set of separation factors for the entire suite of technologies that may be combined together. The user selects whether to use RU-1, RU-2, or DU to blend with this combined TRU-U product stream. The model estimates the required ratio of TRU-U product to U feed for that recycles's iteration. Since the TRU-U product can contain uranium, and the RU streams will typically contain some TRU impurity, the ratio of TRU-U product to U product is not the same as the chemical TRU:U ratio in the final blended product.

The reactor simulation is performed by an internally developed burn-up code MRTAU [1], [6]. 


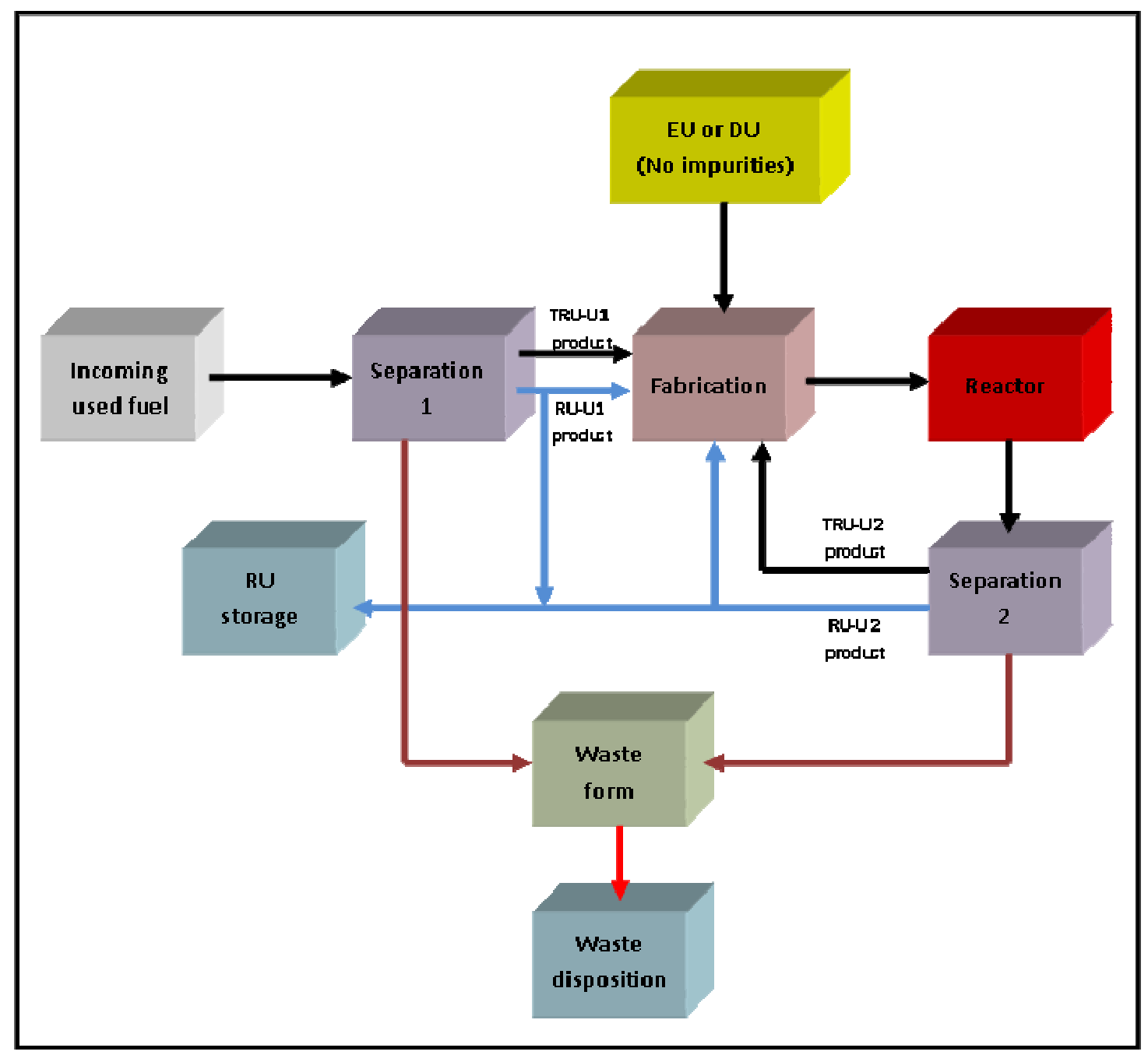

Fig 2.2. FIT basic mass flow.

The code needs two fuel compositions - that of the incoming stream and that for the reactor in the recycle loop. The composition of the incoming stream is used, as is. FIT adjusts the composition of the reference fuel in the recycle loop according to what happens in the simulation. The fuel adjustment in FIT is performed through a standard methodology. The code compares the BOC k-infinitive of the initial recipe (fuel without impurities) with that of the fuel coming from the separation stages (impurity content depending on the separation method [3]), adjusting the TRU:U ratio in order to get the same initial k-infinity. In order to perform this adjustment, FIT uses 1-group not-tabulated cross sections (the cross sections taken from reactor physic calculations performed outside the code).

As mentioned before, the separation stages are simulated through separation factors for each isotope or element families. In order to reproduce the fuel cycle cases (Table 2.1 and Fig. 2.2), analyzed through the reactor physic calculations, the separation matrices have been appropriately modified obtaining the same FP composition for each case. 


\section{RESULTS}

\subsection{SCALE6.1}

The table and figure below show the calculated $P u^{F P}$ and Pu content in MOX fuel assemblies necessary to maintain the same average burnup at discharge of $51 \mathrm{GWd} / \mathrm{tIHM}$ independently of the amount of the FP losses. It shows, in particular, that the mass of Pu in the MOX assembly increases by approximately $3.5 \%$ per $\%$ of FP losses.

NB: The calculations of the necessary $P u^{F P}$ contents showed the presence of what looks like an artifact which seems to be caused by the large number of FP (176) in the initial fuel composition. This issue is currently being addressed by the ScaleHelp team. The values presented in the table below are obtained by subtracting the observed $0.17 \%$ bias on the $P u^{F P}$ content calculated with SCALE. We gratefully acknowledge our colleague Brent Dixon for pointing out the slight irregularities of some results which led us to find this artifact. More information can be found in Appendix 2.

\begin{tabular}{|c|c|c|}
\hline $\begin{array}{c}\text { FP } \\
\text { losses (w\%) }\end{array}$ & $\begin{array}{c}\boldsymbol{P u}^{\boldsymbol{F P}} \\
\text { enrichment (w\%) }\end{array}$ & $\begin{array}{c}\text { Pu } \\
\text { enrichment (w\%) }\end{array}$ \\
\hline- & $10.17 \%$ & $10.17 \%$ \\
\hline 0.25 & $10.37 \%$ & $10.27 \%$ \\
\hline 0.50 & $10.55 \%$ & $10.35 \%$ \\
\hline 0.75 & $10.76 \%$ & $10.45 \%$ \\
\hline 1.00 & $10.94 \%$ & $10.53 \%$ \\
\hline 2.00 & $11.73 \%$ & $10.88 \%$ \\
\hline 3.00 & $12.59 \%$ & $11.28 \%$ \\
\hline 4.00 & $13.53 \%$ & $11.71 \%$ \\
\hline 5.00 & $14.49 \%$ & $12.13 \%$ \\
\hline
\end{tabular}

Table 3.1. $P u^{F P}$ and Pu content in MOX fuel assemblies for different FP losses. 


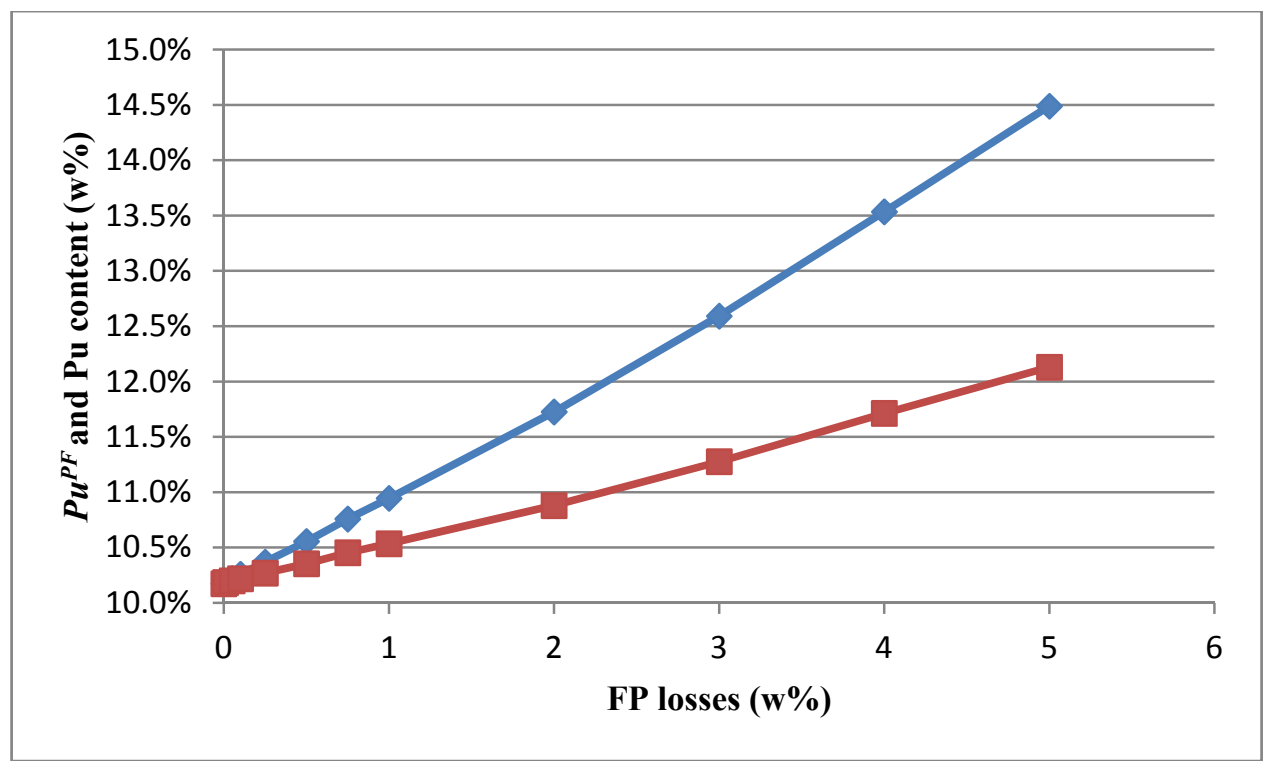

Figure 3.1. $P u^{F P}$ (blue) and Pu (red) content in PWR MOX fuel assemblies calculated with SCALE6.1 for different FP losses.

\subsection{FIT}

As mentioned earlier, FIT uses 1-group cross-sections generated for a reference fuel (in our case the $10.17 \%$ MOX fuel without FP) and estimates the effects of variations of this reference fuel composition using the same 1-group cross-section set. The figure below compares the $P u^{F P}$ contents calculated with FIT with those calculated with SCALE6.1 for FP losses up to 5\%.

The discrepancies have been shown to come not from the constant 1-group cross-section set hypothesis used by FIT but instead from the difference in choosing the reference k-infinity. With SCALE, the necessary $P u^{F P}$ enrichments are determined so that the k-infinities of the assemblies at the average end-of-cycle burn-up are all the same, independently of the FP losses. This is the standard approach used everywhere for these kinds of analyses and it has proved its worth. FIT uses a similar approach but considering the k-infinity of the reference fresh fuel assembly as the target k-infinity that the other fuels must satisfy. This approach is not as valid as the other one because depending on their internal conversion ratio and on their FP reactivity worth, different fuels will necessitate different initial k-infinity to reach the same burnup. For example, a HEU fuel has a higher initial k-infinity than a LEU fuel and a LEU fuel has a higher initial k-infinity than a MOX fuel.

This was demonstrated by calculating the $P u^{F P}$ contents with SCALE but using the FIT "same fresh fuel k-infinity" approach (the green curve on the figure below) instead of the "same end-ofcycle fuel k-infinity" approach and observing that, in this case, both SCALE and FIT gave the same (wrong) $P u^{F P}$ contents. Modifying FIT to take this into account should be doable and it should make it more reliable. 


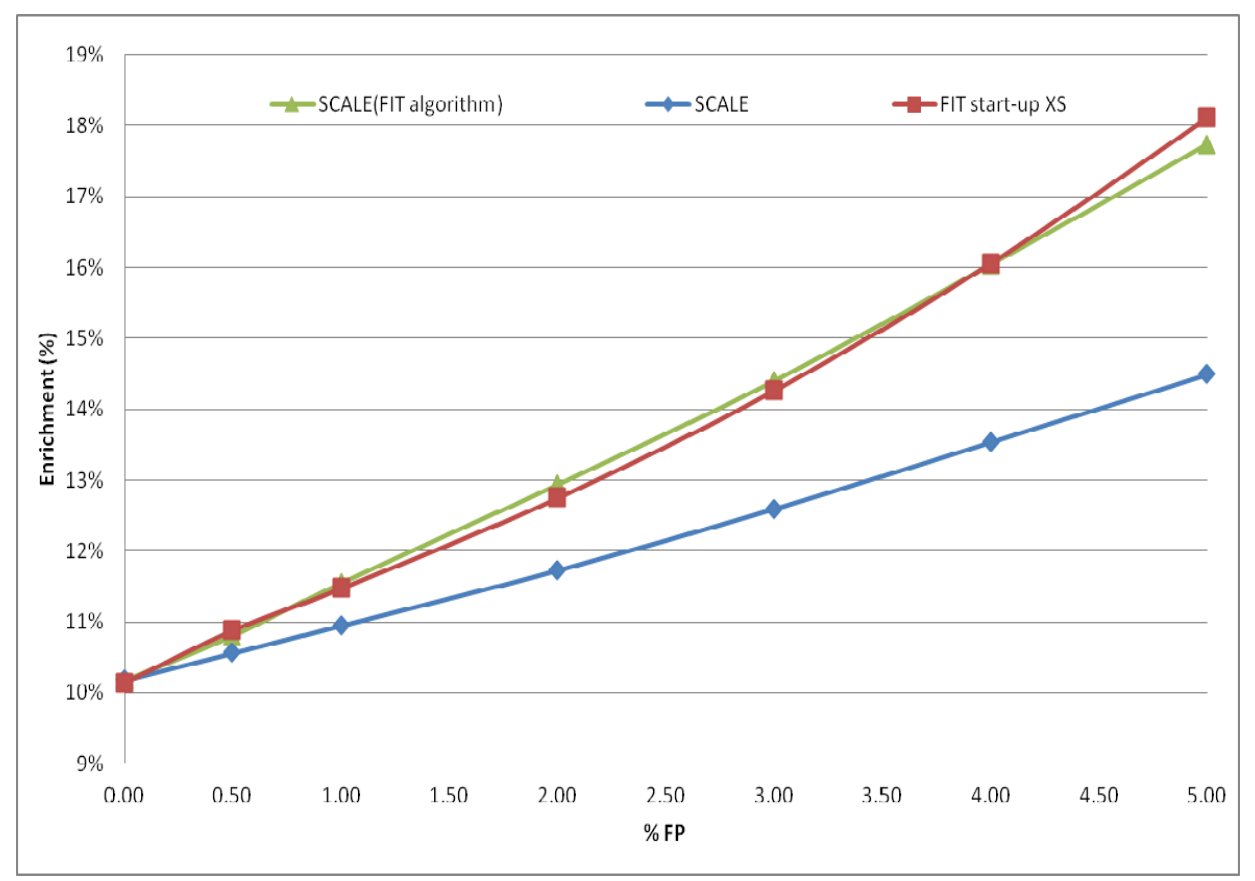

Figure 3.2. Comparison of the $P u^{F P}$ content calculated with FIT and SCALE6.1 for different FP losses.

\section{CONCLUSIONS.}

This report presents the results of a neutronics analysis in which the separation of the fission products (FP) during the reprocessing of UOX spent fuel assemblies (UOX SNF) is not perfect and that, consequently, a certain amount of FP goes into the Pu stream used to fabricate PWR MOX fuel assemblies. In this preliminary analysis, the FP losses are considered elementindependent, i.e. for example, $1 \%$ of FP losses means that $1 \%$ of all non-gaseous FP leak into the Pu stream.

The main objective of these calculations is to quantity the increase of the Pu content of a PWR MOX fuel necessary to maintain the same average burnup at discharge (51 GWd/tIHM) independently of the amount of FP in the Pu stream. The calculations are performed with SCALE6.1 as well as, in order to assess its validity, with the internally developed fuel cycle tool FIT.

The two main conclusions are:

1) The mass of $\mathrm{Pu}$ in the MOX assembly increases by approximately $3.5 \%$ per $\%$ of $\mathrm{FP}$ losses.

2) The "same fresh fuel k-infinity" hypothesis used by FIT causes relatively large errors in the calculation of the Pu contents and should be modified. 


\section{REFERENCES.}

1. A. Alfonsi, S. Bays, C.Rabiti, S. Piet, "Multi-Reactor Transmutation Analysis Utility

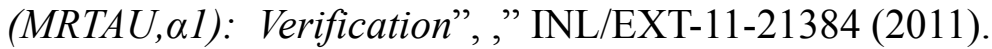

2. S. Bays, S. Piet, M. Pope, G. Youinou, A. Dumontier, D. Hawn, "Transmutation Dynamics: Impacts of Multi-Recycling on Fuel Cycle Performances", INL/EXT-09-16857 (2009).

3. G. Youinou, S. Bays, "A Neutronic Analysis of TRU Recycling in PWRs Loaded with MOXUE Fuel (MOX with U-235 Enriched U Support)", INL/EXT-09-16091 (2009).

4. M. DeHart, "Lattice Physics Capabilities of the SCALE Code System Using TRITON", Physor Conference (2006).

5. S. Piet, N.Soelberg, et al., "Analyzing Losses: Transuranics Into Waste and Fission Products Into Recycled Fuel", INL/CON-10-20136 (2010).

6. A. Alfonsi, C. Rabiti, A. Epiney, Y. Wang, J. Cogliati, "PHISICS TOOLKIT: Multi-Reactor Transmutation Analysis Utility MRTAU”, Physor Conference (2012)

7. S. J. Piet, N. R. Soelberg, et al., "The FIT Model - Fuel Cycle Integration and Tradeoffs", INL/EXT-10-20190 (2011).

8. L.Gauld, O. Herman, et al., "Origen-S: Scale system module to calculate fuel depletion, Actinide transmutation, fission product buildup and decay, and associated radiation source terms", Oak Ridge National Laboratory (2009). 
Appendix 1: List of non-gaseous fission products considered in the calculations.

\begin{tabular}{|c|c|c|c|c|c|c|c|}
\hline \multicolumn{8}{|c|}{ Number of isotopes $=176$} \\
\hline Li6 & Rb87 & Mo96 & Ag109 & Sn123 & Cs134 & $\mathrm{Nd143}$ & Eu156 \\
\hline Li7 & Sr86 & Mo97 & Ag110m & Sn124 & Cs135 & Nd144 & Gd152 \\
\hline Be9 & Sr87 & Mo98 & Ag111 & Sn125 & Cs136 & Nd145 & Gd153 \\
\hline N14 & Sr88 & Mo100 & Cd106 & Sn126 & Cs137 & Nd146 & Gd154 \\
\hline Ga69 & Sr89 & Tc99 & Cd108 & Sb121 & Ba132 & Nd147 & Gd155 \\
\hline Ga71 & Sr90 & Ru98 & Cd110 & Sb123 & Ba134 & Nd148 & Gd156 \\
\hline Ge70 & Y89 & Ru99 & Cd111 & Sb124 & Ba135 & Nd150 & Gd157 \\
\hline Ge72 & Y90 & Ru100 & Cd112 & Sb125 & Ba136 & Pm147 & Gd158 \\
\hline Ge73 & Y91 & Ru101 & Cd113 & Sb126 & Ba137 & Pm148 & Gd160 \\
\hline Ge74 & Zr90 & Ru102 & Cd114 & Te122 & Ba138 & Pm148m & Tb159 \\
\hline Ge76 & Zr91 & Ru103 & Cd115m & Te123 & Ba140 & Sm147 & Tb160 \\
\hline As75 & Zr92 & Ru104 & Cd116 & Te124 & La138 & Sm148 & Dy160 \\
\hline Se76 & Zr93 & Ru106 & $\ln 113$ & Te125 & La139 & Sm149 & Dy161 \\
\hline Se77 & Zr94 & Rh103 & $\ln 115$ & Te126 & La140 & Sm150 & Dy162 \\
\hline Se78 & Zr95 & Pd102 & Sn114 & Te127m & Ce140 & Sm151 & Dy163 \\
\hline Se79 & Zr96 & Pd104 & Sn115 & Te128 & Ce141 & Sm152 & Dy164 \\
\hline Se80 & $\mathrm{Nb93}$ & Pd105 & Sn116 & Te129m & Ce142 & Sm154 & Ho165 \\
\hline Se82 & Nb94 & Pd106 & Sn117 & Te130 & Ce143 & Eu151 & Ho166m \\
\hline Br79 & Nb95 & Pd107 & Sn118 & I127 & Ce144 & Eu152 & Er166 \\
\hline Br81 & Mo92 & Pd108 & Sn119 & 1129 & Pr141 & Eu153 & Er167 \\
\hline Rb85 & Mo94 & Pd110 & Sn120 & I131 & Pr143 & Eu154 & Er168 \\
\hline Rb86 & Mo95 & Ag107 & Sn122 & Cs133 & Nd142 & Eu155 & Er170 \\
\hline
\end{tabular}




\section{Appendix 2: SCALE 6.1 issue.}

In our simulations we noticed the presence of a bias on the requested $P u^{P F}(\mathrm{Pu}+\mathrm{x} \%$ FP) enrichment moving from the MOX reference case $(0.0 \% \mathrm{FP})$ to the impurity cases. Indeed, the slightest addition of FP (we used 176 non-gaseous FP) in the initial MOX fuel composition causes a jump of about $0.17 \%$ on the necessary enrichment followed by a linear increase as shown on the figure below.

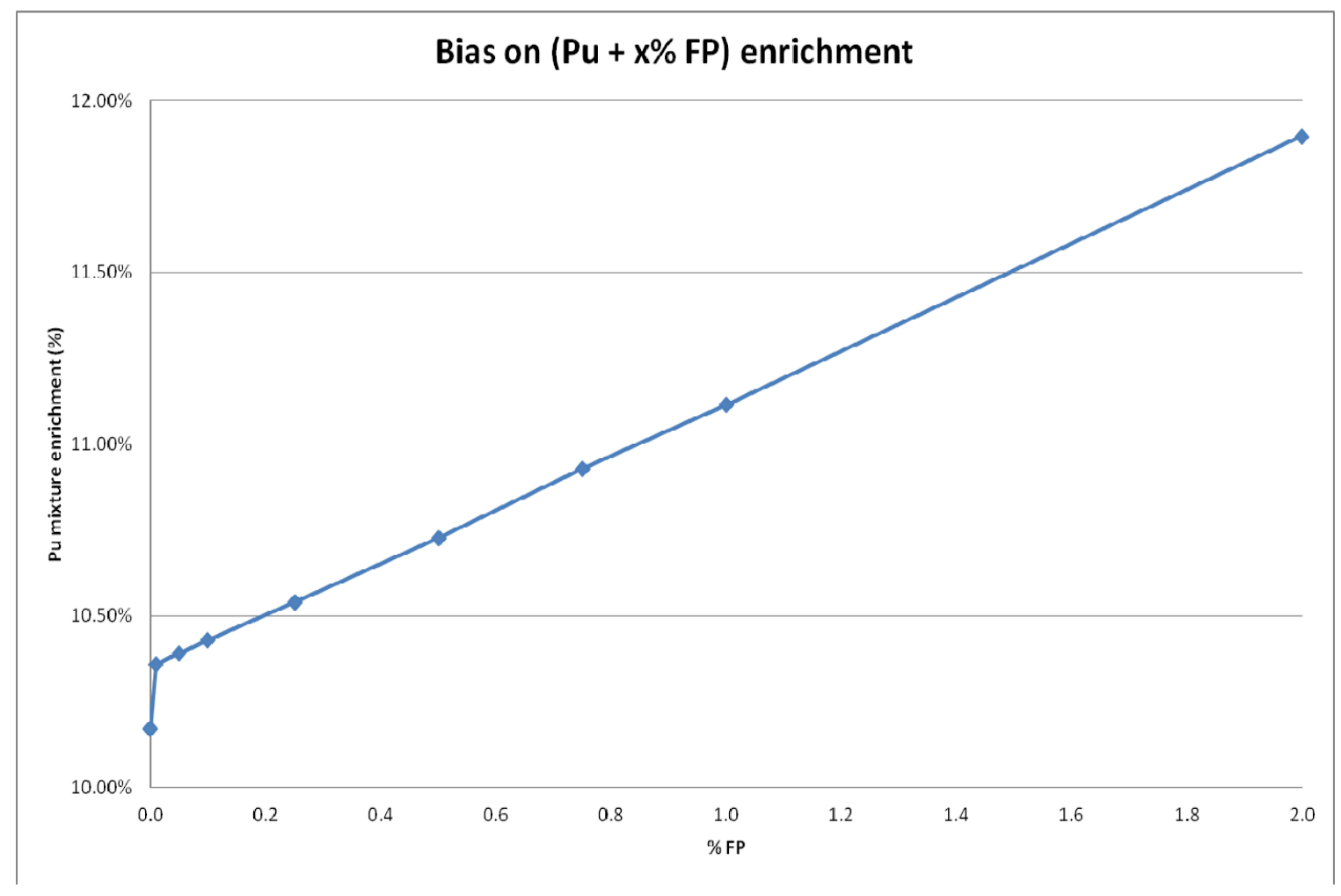

Necessary $P u^{F P}$ content calculated using 176 FP

In order to prove that the artifact was really present, we needed to perform a few more simulations. We decided to reduce the number of isotopes input in SCALE 6.1, keeping the 12 most important, in terms of neutron poisoning, fission products (see table below). These isotopes represent a contribution on the poisoning of about $60 \%$ even if the FP total mass is only $15 \%$ of the full isotope set cases.

\begin{tabular}{|c|c|c|c|c|c|}
\hline \multicolumn{5}{|c|}{ Twelve most important neutron poisons } \\
\hline Tc99 & Cs133 & Pm147 & Sm150 & Sm152 & Eu152 \\
\hline Rh103 & Nd143 & Sm149 & Sm151 & Sm154 & Eu153 \\
\hline
\end{tabular}

Most important FP 
The requested $P u^{F P}$ contents computed for these cases (see figure below) tend to show that the jump observed is indeed an artifact caused by the large number of isotopes input in the code. This gave us the possibility to simply subtract the bias of $\mathbf{0 . 1 7 \%}$ from the enrichment curve of the full FP set cases.

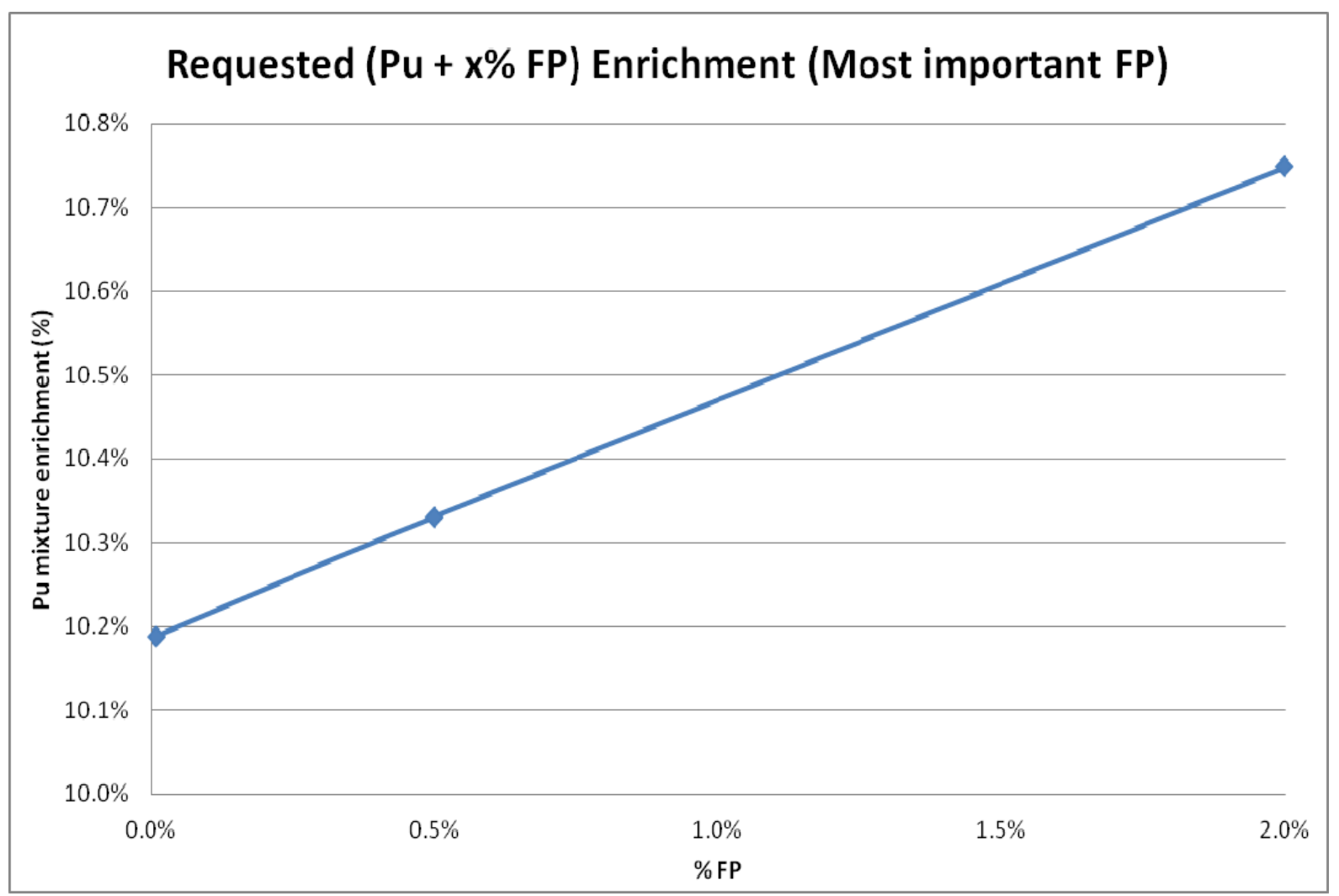

Necessary $\mathrm{Pu}^{\mathrm{FP}}$ content calculated using only the 12 most important FP 